\title{
SMART ADVISORY SYSTEM FOR URBAN MOBILITY SCHEME: SOUTH EAST ASIA EXPERIENCES
}

\author{
RESDIANSYAH ${ }^{1}$
}

DOI: 10.21163/GT_2019. 141.25

\begin{abstract}
:
Urban mobility refers to a sustainable transport that gives the least impact in terms of social and environmental but at the same time is able to supply energy sources globally that includes non-motorized transport strategies deployment also known as Mobility Management Scheme (MMS). As new road development cannot help solve the congestion problem, past research has shown that MMS is an effective measure to mitigate congestion. MMS consists of different strategies that subdivided into categories according to how they are able to influence urban travel behavior. Determining appropriate strategies requires transportation expert. Unfortunately, very few experts can be considering as adviser, and are unlikely to be available at all times. Development of new version of Smart Advisory System (SAS) in order to assist policy maker would be a valuable tool. This research has successfully developed new SAS based on human expertise using Kappa-PC shell version 2.4. The process of knowledge acquisition and selection of MMS strategy has been encoded in a knowledge-based system. The newly developed SAS was successfully verified, validated and evaluated (VV\&E) using Turing test by comparing the result output with the real expert recommendation from South East Asia in which the findings suggested favorable results for the system.
\end{abstract}

Key-words: Mobility Management Scheme (MMS), Smart advisory system, Shell expert system, Urban mobility.

\section{INTRODUCTION}

Demand for travel increases with the assumption that private cars are easy (accesibility), comfortable, door to door services and judge by traveler as the only solution for mobility. From those assumption, accesibility play major important role since hold as a key concept of the actual territorial planning strategies as it represents a major driving force of the socio-economic development of a region. In order to compete with private car in term of accesibility, public transport need to consider variables related to distance, slope of the routes and public transport availability (Corodescu, 2014). In addition, supplies for infrastructure development such as roads are significantly increase and this is proportional to the increase in traffic volume. In addition to the most important accessibility procedure, the route could be designed according to the automatic hierarchy of destinations according to certain criteria such as price, distance, attractiveness or emergency cases (Nicoara \& Haidu, 2014; Dudás et al., 2017). At one point, the supply will not be able to meet demand, due to certain factors such as budget problems, limited land or space. On the other hand, although the construction of new roads to increase road capacity may reduce some of the effects of congestion but the benefits can only be matched by the growth of controlled traffic volume. Therefore, another alternative is to implement the Mobility Management

\footnotetext{
1 Pembangunan Jaya University, Center for Urban Studies, Bintaro, South Tangerang, Indonesia, resdiansyah.mansyur@upj.ac.id;
} 
Scheme (MMS), i.e. to ensure that people are still traveling but at the same time reducing the use of private cars (Litman, 2013).

In addition, the MMS application initiative will encourage people to reduce the number of trips they travel, travel frequently but use alternatives to driving alone, riding outside peak hours, and overall reducing the length of the trip they make. The main purpose of MMS is to minimize travel by private vehicle during peak hours and at the same time reduce the need for new road construction. On the other hand, MMS measures make driving alternatives more attractive, build a positive public attitude towards these alternatives, and provide information and incentives to encourage responsible travel behavior. The Mobility Management Scheme (MMS) and vehicle Miles of Travel [VMT] refers to a policy and program that can transform travel activities to achieve planning goals and improve the efficiency of a transportation system (Litman, 2013).

\section{HOW ADVISORY SYSTEM CAN HELP US}

According to Papaioannou and Georgiou (2003), MMS measures comprise different types of interventions mainly in urban areas that aim at reducing transport demand during the day or during a specific time period. The idea in any cases is that MMS measures discourage people from excessive and irrational use of private cars, they cause mode shift to environmentally friendly modes and thus they result in better traffic and environmental conditions. In this respect many research efforts have been undertaken recently in several urban areas from different countries around the world to study the impacts and the effectiveness of such measures. Since transport demand is created from the people who travel to satisfy a need, certain MMS measures target at the reduction of these needs. Other measures again focus on the time differentiation of travel needs so that better exploitation of existing capacity can be achieved in time and in space. In recent year, the MMS application guide manual has increasingly accepted as a tool for reducing traffic congestion during peak hours and reducing air pollution problems. A number of documents are available to guide people in implementing and marketing MMS programs, but few guidelines are offered regarding MMS program planning and how to select appropriate and efficient MMS strategies.

Consequently, many MMS strategies are ineffective and developed with inefficient trial and error. Furthermore, the implementation of an MMS strategy requires an expert or advisor, as with their knowledge they can provide advice on the most appropriate MMS strategy based on their location and location details. Unfortunately, very few expert people can be considering as adviser, and are unlikely to be available at all times. These experts are not always there, nor do they always have time to consult all possible references, review existing data, etc. (Zain et al., 2005). This will lead to time-consuming scheduling and interview scheduling, thus delaying a project. There is also the possibility that there may be no advisors left behind after death, as most of them are in elderly age. Later on, it is a burden for Junior Engineer to refer to the book as part of their references to find solutions in implementing MMS (Zain et al., 2005). On the other hand, Zain, Islam and Basri (2005) stated also in their research that the advisory system has the potential to capture such expertise. The development of smart advisory systems is design to help employers, developers, junior transportation engineers, city council officers, property owners and managers, transportation management associations (TMAs), and MMS consultants. This SAS suggests the process of implementing MMS, and offers guidance and advice on selecting the most effective MMS strategies. This will help provide a specific picture for 
choosing a more effective and appropriate MMS strategy in a shorter time and with less frustration. This will give an overview of a "big picture" of the MMS strategy, and then guide us to identify what strategies make sense to us, and in determining how many strategies we need to achieve the desired or necessary travel reductions. In summary, development of a smart advisory system for implementing suitable strategy in MMS in order to assist junior engineer and the policy maker in MMS would be a valuable tool. The development of a smart advisory system requires both knowledge from transport and software engineers. Software engineers will develop an advisory system based on civil engineer's knowledge, sources from books and interview adviser persons for implementations of MMS. Therefore, it is crucial to have knowledge from both fields in order to develop an advisory system as neither can do it alone.

\section{SYSTEM ARCHITECTURE OF SAS}

\subsection{Knowledge Engineering}

There are currently two ways of building an advisory system. They can built from zero, or using development software known as "shell". Although there are different styles and methods of knowledge engineering, the approach was the same: Knowledge Engineers (KE) interview and observe human expert or a group of expert people as domain and know what their intellectual think, and how they practice their knowledge. KE then translate that knowledge into computer-usable languages, and design inferencing machines, the structure of reasoning, which uses knowledge appropriately. KE will determines how to integrate the use of uncertain knowledge in the reasoning process, and what kind of explanation is useful for the end user.

\subsection{Knowledge Acquisition of SAS}

Acquiring expert knowledge is a crucial component of knowledge engineering. This phase is difficult and time consuming. It is the process of gathering the relevant information about a domain, usually from an expert (De Kock, 2003). The Victoria Transport Institute handbook and encyclopedia, Kuala Lumpur City Council Plan 2020 in MMS section, expert domain in MMS and practitioners in MMS accumulated massive knowledge about advisory system from its involvement and experience planning and devised of MMS practice and application in many countries in the world especially in SEA. Those parties involved in massive knowledge as stated above are primary knowledge source for this project.

\subsection{Knowledge Abstraction and Representation of Advisory System}

In an advisory system, knowledge means the information that a computer system needs before an advisory system can be intelligent. It needs to extract it first from the source of knowledge and then represented in a way that can be manipulate by the computer very efficiently. One is using rule-based representation. This method uses the conditions of IF and THEN statement actions to represent knowledge. When conditions in the IF section are met or adjusted, the rules will be eliminated and the actions determined by the THEN section are then triggered. Another representation method of knowledge is frame-based. It uses a network of classes and instances that are link by a relation and organize into a hierarchical structure. Fig. 1 shows the relationship between classes and samples. 


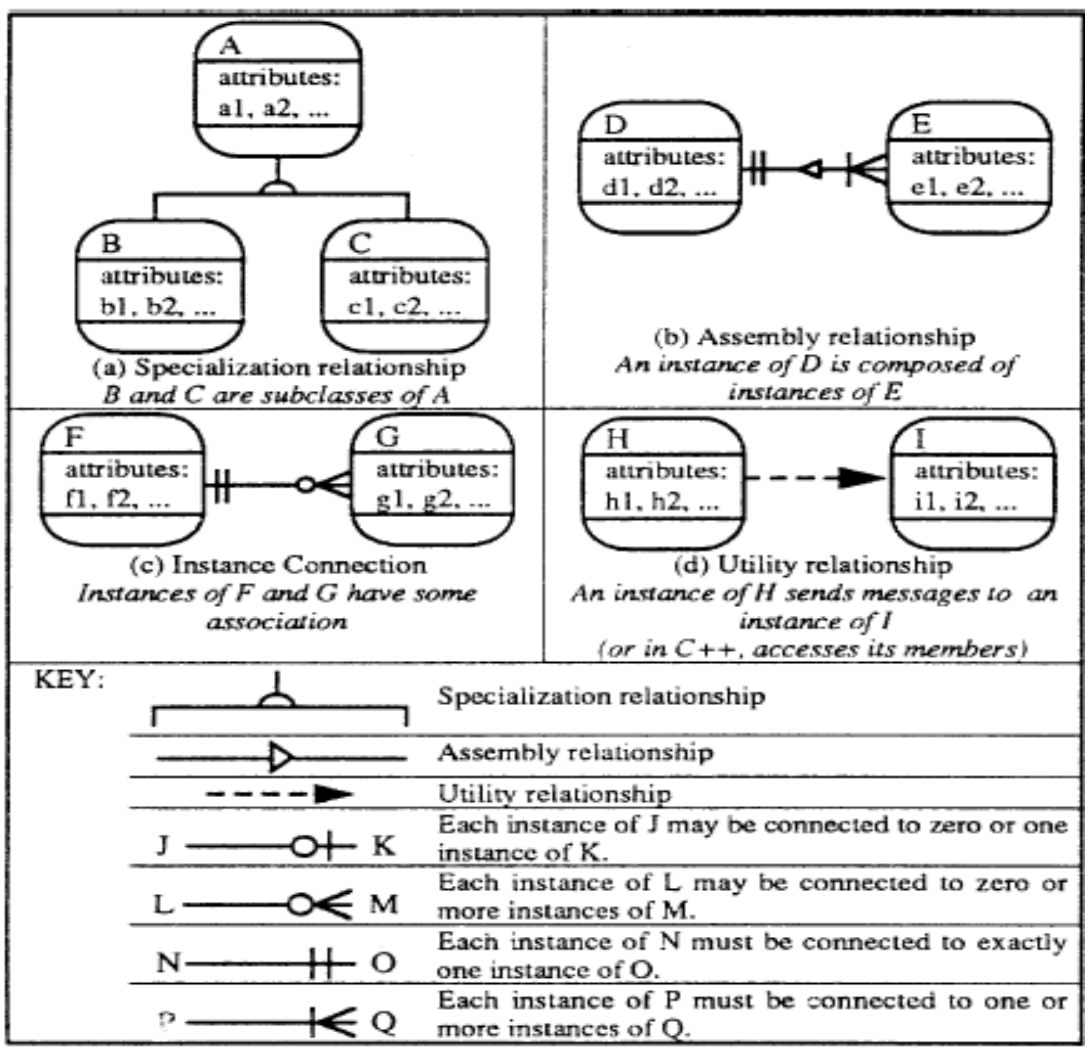

Fig. 1. Class and Instance Relationship.

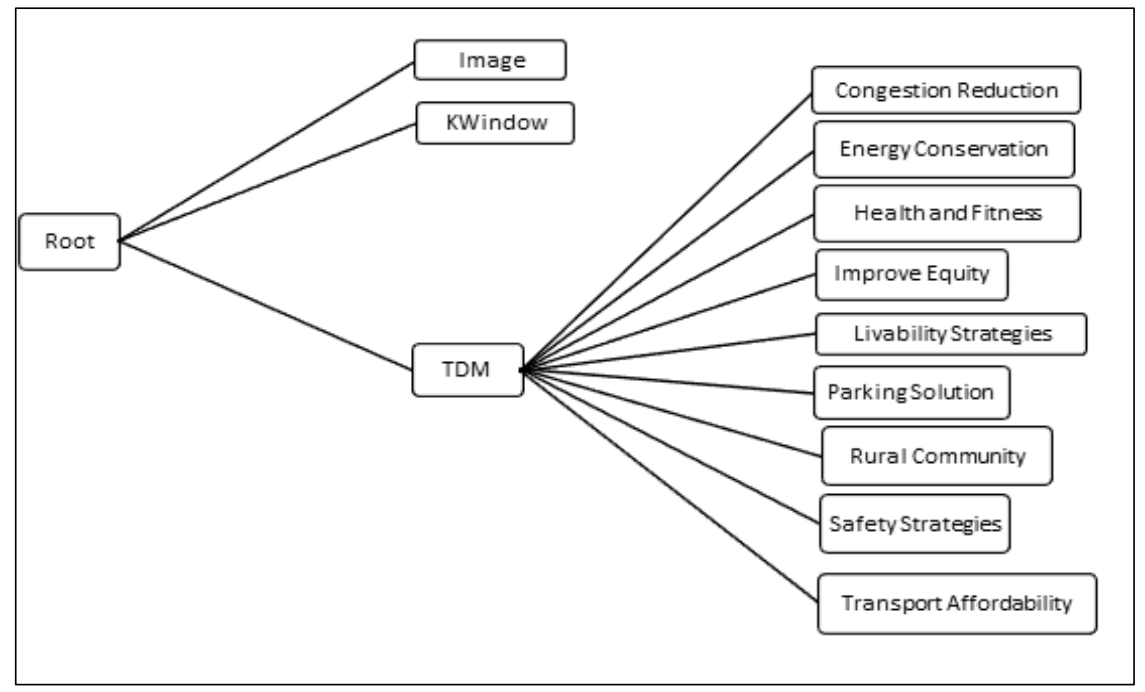

Fig. 2. Top-level Object Hierarchy of the SAS. 
Each node is represented by a concept that can be translated by attributes and/or values associated with that node. This class and relationship chart is used in order to develop the logical thinking in advisory system include the hierarchical structure as can be seen in Fig. 2. The topmost node represents the general concept and the node underneath represents a more specific concept. In this research, shell-based software has been used.

This software supports both methods of knowledge representation. However, the nature of the advisory system in MMS makes this frame-based representation more efficient and broad-minded. In order to develop SAS (Smart Advisory System) for MMS (Mobility Management Scheme) strategy with thousand databases of MMS which is becomes the backbone of this software system, taxonomic process has been applied. The uppermost class was labeled as MMS, which has a broad meaning and includes all the strategies involved in MMS. Furthermore, it is group into nine subclasses: congestion reduction, energy conservation, health and fitness, equity enhancement, livability strategies, parking solutions, rural communities, safety strategies, and affordability. All of these subclasses represent the main objectives in the MMS strategy application. Each of the nine subclasses is dividing into three more detailed subclasses, which are part of the main categories of MMS namely better transportation options, incentives to use alternative modes and reduce driving, and land-use management. The final subclasses represent eight geographical areas for each three previous subclasses; large urban, urban, suburban, town, rural, commercial center, residential, and resort. Under each geographical area subclass, there are three instances indicate the most suitable MMS strategies to be implemented according to its hierarchy.

\subsection{Tools, Shells and Skeletons}

There are many tools exist in developing an advisory system. Three main categories are divided in the major tools used in practice: programming language, programming environment and an advisory system shells. Selection of Kappa PC software is due to suitability in designer mode, which gives the knowledge engineer the possibility to code the knowledge base in a graphical (easily readable and editable) way that follows the latest trends in user interface. It lets the engineer decide what method to use for coding the knowledge, thereby addressing more complex problems. There is an opportunity to evaluate the shell system being built prior to the proposed advanced development, ie with access to a series of sample applications, and this has been recommended as a fairly effective tool for development. Furthermore, shell-based advisory systems are preferred because they offer easy manipulation in the development, increased productivity and true windowing capabilities to run on personal computers. Building an advisory system using a shell has a very significant advantage. A system can be built to perform a unique task by injecting all the necessary knowledge of the task domain into the shell. An inference engine that applies knowledge to the task is built into its shell. If the program is not too complicated and if an expert has some training in the use of shells, then the expert can enter his own knowledge into the shell that has been built.

\subsection{Domain Acquaintance}

It is important for a knowledge engineer (KE) to have a good understanding of the domain to improve the construction of prototypes with respect to feasibility and evaluation (Basri, 2000). The first and most important step for knowledge engineers is to gain expertise in knowledge techniques. 


\subsection{Domain Expert}

A domain or expert is a knowledgeable person who has a brilliant reputation for producing the best solution for problems in a particular field. Experts use strategies, tricks and shortcuts to find solutions efficiently, through a consultation system by modeling a problem-solving strategy. A person's ability to serve as an intelligent domain will depend on the person's characteristics such as the ability to explain important knowledge or heuristics, be introspective, patient, and communicate effectively.

\subsection{Source the Knowledge Base}

A Knowledge-based in SAS uses human knowledge to solve problems that normally would require human intelligence (Tripathi, 2011). The main knowledge was obtained through communication with the transportation experts and engineers who involved directly with the MMS strategy and implementation. The domain experts were selected from experienced MMS planner from several countries in South East Asia. More than 30 transportation experts are involved in this project. These experts were chosen from individuals who were currently practicing MMS in their city and some transportation expert from university who had involved in transportation field for many years. On the other hand, the selection of domain experts also critically depending on the expert's availability (time), possess of good communication skills, willingness to participate, and acknowledged as smart by the community or by their peers. Due to time constrains, most of the interview and consultations with the domain experts were done through questionnaire and if knowledge engineer successful to interview the expert, it is done informally and not recorded by tape due to certain reason that expert's not comfortable if the interview recorded by tape. The questionnaire was designed in such a way to covered all nine main objectives in MMS which were obtained previously through different sources from text books and manuals.

\subsection{Object Representation of SAS}

The browser window object in Fig. 2 represents a top-grade hierarchy in the object model developed for the Smart Advisory System domain. The class represents the entire prototype consisting of nine major subclasses.

\subsection{User Interface Design and Example of SAS Module}

Kappa-PC provides a great tool for creating graphical user interfaces. In addition to session windows, standard images, special menus, and dialog windows, it can import Visual Basic (VBX) controls to meet the specific requirements of knowledge engineers. The graphical user interface starts with a common information interface that is the first window when SAS launches, as shown in Fig. 3. It contains information about SAS titles, developers, serial numbers, and development dates. Fig. 4 shows screen snapshots example of one module in SAS. Furthermore, when all instruction in SAS has been applied, finally system will give advice strategy summary which show feature of the travel impact, benefit and equity. Based on the travel impact summary, user can easily to identified how effective reduction of trip or total traffic which is stated in the summary using the rating scale; rating from 3 (very beneficial) to -3 (very harmful); 0 indicates no impact or mixed impact on the objective if user implement this strategy. If the user confirmed chooses this menu as most suitable strategy, then by clicking PRINT button, user can view notepad text editor with analysis result (rating scale) as shown in Fig. 5. 


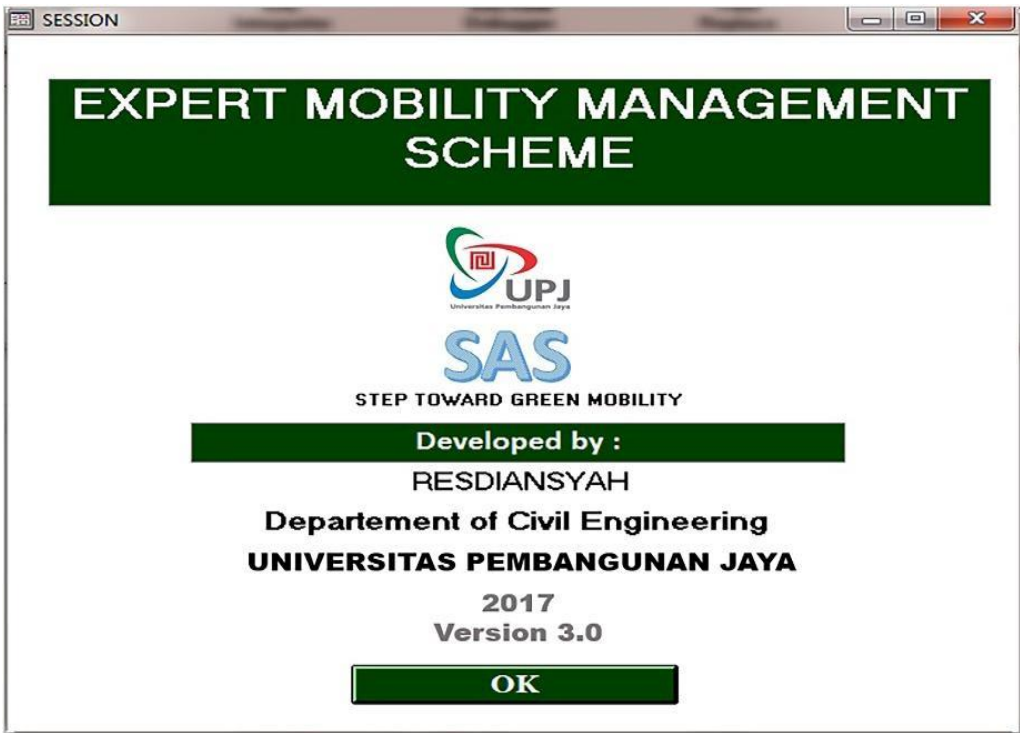

Fig. 3. General information interface.

\section{SAS}

Expert Mobility Management Scheme

What is your main objective of implementing TDM?

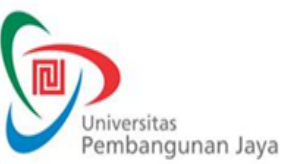

(Please select your objective to view its description)

Congestion Reductions

- Energy Conservation and Emission Reduction

Health and Fitness

Improving Quality

Livability Strategies

Parking Solutions

Rural Community

Safety Strategies

Transportation Affordability

\section{Description}

Energy conservation is one of objective in implementation of TDM strategies for reducing vehicle energy consumption and pollution emissions.

This objective identifies and evaluates various strategies to reduce transport energy consumption and pollution emissions. These include Transportation Demand Management strategies that affect travel behaviour; incentives for more efficient and less polluting vehicles; alternative fuels; methods to identify; repair and scrap high-emiting vehicles; regulations; pricing and information programs

Energy conservation is the practice of decreasing the quantity of energy used. It may be achieved through efficient energy use, in which case energy use is decreased while achieving a similar outcome, or by reduced consumption of energy services. Energy conservation may result in increase of financial capital, environmental value, national security, personal security, and human comfort, individuals and organizations that are direct consumers of energy may want to conserve energy in order to reduce energy costs and promote economic security. Industrial and commercial users may want to increase efficiency and thus maximize profit.

(If you are sure with your selection, please click NEXT)

Fig. 4. Screen snapshots example of one module in SAS. 


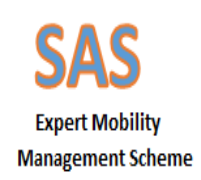

Management Scheme

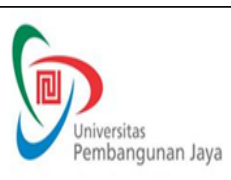

ADVISE STRATEGY FUEL TAXES

\begin{tabular}{|l|c|l|}
\hline \multicolumn{3}{|c|}{ Travel Impact Summary } \\
\hline \multicolumn{1}{|c|}{ Objective } & Rating & \multicolumn{1}{|c|}{ Comments } \\
\hline Reduces total traffic & 2 & $\begin{array}{l}\text { Has a modest impact on } \\
\text { vehicle travel }\end{array}$ \\
\hline $\begin{array}{l}\text { Reduces peak period } \\
\text { traffic }\end{array}$ & 1 & $\begin{array}{l}\text { Peak-period travel tends } \\
\text { to be less price sensitive } \\
\text { than off-peak travel }\end{array}$ \\
\hline $\begin{array}{l}\text { Shifts peak to off- } \\
\text { peak periods }\end{array}$ & 0 & \\
\hline $\begin{array}{l}\text { Shifts automobile } \\
\text { travel to alternative } \\
\text { modes }\end{array}$ & 1 & $\begin{array}{l}\text { Provides a modest } \\
\text { incentive to shift mode }\end{array}$ \\
\hline $\begin{array}{l}\text { Improves access, } \\
\text { reduces the need for } \\
\text { travel }\end{array}$ & & \\
\hline $\begin{array}{l}\text { Increased } \\
\text { ridesharing }\end{array}$ & 1 & \\
\hline $\begin{array}{l}\text { Increased public } \\
\text { transit }\end{array}$ & 1 & \\
\hline Increased cycling & 1 & \\
\hline Increased walking & 1 & \\
\hline Increased Telework & 1 & $\begin{array}{l}\text { Reduces freight } \\
\text { traffic }\end{array}$ \\
\hline
\end{tabular}

Rating from 3 (very beneficial) to -3 (very harmful). $A 0$ indicates no impact or mixed impacts

\begin{tabular}{|c|c|c|c|c|c|}
\hline \multicolumn{3}{|c|}{ Benefit Summary } & \multicolumn{3}{|c|}{ Equity Summary } \\
\hline Obejctive & Rating & Comments & Impacts & Rating & Comments \\
\hline Congestion Reduction & 1 & $\begin{array}{l}\text { Modest reduction in vehicle } \\
\text { travel }\end{array}$ & $\begin{array}{l}\text { Treats everybody } \\
\text { equally }\end{array}$ & -1 & $\begin{array}{l}\text { Some groups (i.e. Rural } \\
\text { residents) bear greater } \\
\text { costs than others } \\
\end{array}$ \\
\hline Road \& Parking Savings & 2 & $\begin{array}{l}\text { Modest reduction in vehicle } \\
\text { size and travel }\end{array}$ & $\begin{array}{l}\text { Individuals bear the } \\
\text { costs they impose }\end{array}$ & 2 & $\begin{array}{l}\text { Increases the portion of } \\
\text { vehicle costs recovered } \\
\text { through user fees }\end{array}$ \\
\hline Consumer Savings & -1 & $\begin{array}{l}\text { Increases vehicle operating } \\
\text { costs. Overall impact depend } \\
\text { on how revenues are used }\end{array}$ & $\begin{array}{l}\text { Progressive with } \\
\text { respect to income }\end{array}$ & -1 & $\begin{array}{l}\text { Fuel taxes are regressive, } \\
\text { but overall impacts } \\
\text { depend on how revenues } \\
\text { are used }\end{array}$ \\
\hline Transport Choice & -1 & $\begin{array}{l}\text { Mixed. Driving becomes less } \\
\text { affordable, but may increase } \\
\text { support for alternative }\end{array}$ & \begin{tabular}{|l} 
Benefits \\
transportation \\
disadvantaged
\end{tabular} & 3 & $\begin{array}{l}\text { Can reduce roadway } \\
\text { expenses bome by non- } \\
\text { drivers, and encourages }\end{array}$ \\
\hline Road Safety & 0 & $\begin{array}{l}\text { reduced driving may be } \\
\text { offset by use of smaller cars } \\
\text { that offer less occupant }\end{array}$ & $\begin{array}{l}\text { Improves basic } \\
\text { mobility }\end{array}$ & 0 & No significant impact \\
\hline \begin{tabular}{|l|} 
Environmental \\
Protection \\
\end{tabular} & 3 & \begin{tabular}{|l|}
$\begin{array}{l}\text { Significant reduction in fuel } \\
\text { use and related pollutants }\end{array}$ \\
\end{tabular} & & & \\
\hline Efficient Land Use & 1 & $\begin{array}{l}\text { Modest reduction in vehicle } \\
\text { travel }\end{array}$ & & & \\
\hline Community Livability & 2 & travel and vehicle size & & & \\
\hline \multicolumn{6}{|c|}{$\begin{array}{l}\text { Rating from } 3 \text { (very beneficial) to }-3 \text { (very harmful). A0 } \\
\text { indicates no impact or mixed impacts }\end{array}$} \\
\hline
\end{tabular}

Fig. 5. Screen snapshots example of one module in SAS.

\section{VERIFICATION, VALIDATION AND EVALUATION}

Prototype testing through VV\&E is the process of evaluating system performance and validating the usefulness of the program and revising it as needed. Testing this prototype also involves how easy the user interfaces and understands the resulting explanatory text (Basri, 2010). A Smart Advisory System (SAS) is correct when it is complete, consistent, and satisfies the requirements that express expert knowledge about how the system should behave. For real-world knowledge bases containing hundreds of rules, however, these aspects of correctness are hard to establish. There may be millions of distinct computational paths through SAS, and each must be dealt with through testing or formal proof to establish correctness (Azar and Alizadeh, 2013). According to Preece (2001), there is often confusion about the distinction between validation and verification, but the conventional view is that verification is the process of checking whether the software system meets the specified requirements of the users, while validation is the process of checking whether the software system meets the actual requirements of the users. 
The verification starts with learning the behavior of SAS under different sub-module in order to study the consistency and stability of the system. In the SAS, there are nine different sub-modules which are dealing with the same specific aims to achieve main goal or objective of MMS strategies. The first scenario was the application of first sub-module under Congestion Reduction and applied to specific aims of Improve Transport Option. When the input was selected then the system will have presented the description of Improved Transport Option in the dialog box. This description should appear as same information when input was selected for second sub-module for Energy Conservation with same specific aims (Improved Transport Option). The results were identical between the different input scenarios. When testing continued to the other seven sub-modules, the SAS still maintain the consistency. Hence, this reflects high stability and reliability of the developed system. The validation result shows that an average $74 \%$ matched between SAS decision and evaluators who are also transport specialist as shown in Table $\mathbf{1 .}$

Table 1. Validation result of SAS.

\begin{tabular}{llll}
\hline & ITO & UALT & $\begin{array}{l}\text { LUM } \\
\text { AVG }\end{array}$ \\
\hline CONGESTION REDUCTION & $82 \%$ & $75 \%$ & $88 \%$ \\
& & & $82 \%$ \\
ENERGY CONSERVATION & $87 \%$ & $75 \%$ & $\begin{array}{l}80 \% \\
81 \%\end{array}$ \\
HEALTH AND FITNESS & $85 \%$ & $78 \%$ & $83 \%$ \\
IMPROVING EQUITY & $80 \%$ & $75 \%$ & $73 \%$ \\
LIVABILITY STRATEGY & $67 \%$ & $65 \%$ & $76 \%$ \\
& & & $66 \%$ \\
PARKING SOLUTIONS & $75 \%$ & $72 \%$ & $66 \%$ \\
& & & $71 \%$ \\
RURAL COMMUNITY & $70 \%$ & $60 \%$ & $62 \%$ \\
SAFETY STRATEGY & & & $64 \%$ \\
TRANSPORT AFFORDABILITY & $77 \%$ & $80 \%$ & $76 \%$ \\
& & $69 \%$ & $75 \%$ \\
& & TOTAL & $74 \%$
\end{tabular}

ITO : IMPROVED TRANSPORT OPTION

UALT: USE ALTERNATIVE MODES \& REDUCE DRIVING

LU: LAND USE MANAGEMENT

This result has been exceeded the expectation in software performance which is expected only around $50 \%$ matched with the expert decision and suggestion since the strategy is very subjective to evaluate and every single expert either domain expert or evaluator who involved in validation process has different experiences in implementing of MMS strategies. The percentage accuracy in this system is the level of performance that is acceptable to the users is called an acceptable performance range, and must be determined at a particular development stage (Basri, 2010). 
This can be determined by a third party, government agency or project sponsor. In this case, acceptable performance ranges have been determined by several countries in Southeast Asia with a range of $50 \%$ to $60 \%$ gained during the knowledge acquisition process. This suggests that the possible use of SAS as an advisory system is very encouraging. Thus, we can say that the developed system has achieved its designed objectives. Generally, the flow of consultation sessions or suggestion sessions between users and the SAS system was quite satisfactory. Users can learn each description in the MMS strategy and can get recommendations provided by the system. The system also allows the user to see the impact of selecting specific strategies before making a decision on the appropriate MMS strategy in order to apply it to a particular situation based on the selected input.

The SAS interface was built to accommodate all parameters and variables as stated above and the interface built was considered to be adequate in its design and functioning. The form of evaluation has been designed and distributed to the evaluators who are involved in transportation project also end-users who are categorized as young and inexperienced transport engineer. Based on the evaluation form result, it shows that the features and interface was acceptable to the transportation experts and the end-users. A very user friendly piece of software/system for inexperience transport engineer has been concluded by certain evaluator as overall performance of the SAS. As a new working prototype (version 3.0), the SAS has a degree of user-friendliness compare to previous version (1.0 and 2.0) which is more acceptable for the most of intended users who has evaluated this software.

\section{CONCLUSION}

The successful development of a new smart advisory system (version 3.0) for implementations of MMS demonstrates that the application in this domain is promising since close to $75 \%$ result from the smart system match with what expert decision. Since the knowledge in this domain is dynamically growing, the SAS is by no means complete at this stage.

\section{REFERENCES}

Azar, A. G. \& Alizadeh, Z. (2013), A basic proof method for the verification, validation and evaluation of expert systems. International Journal of Information Systems and Telecommunication Engineering, 1(1), 27-31.

Basri, H. (2010), A smart advisory system for landfill leachate management. Environmental Technology, 21(2), 157-166.

Corodescu, E (2014), GIS approach in assesing the rural space accesibility-case study: Vaslui County, Romania, Geographia Technica, 9 (1), 20-30.

De Kock, E. (2003), Expert systems and knowledge acquisition Chapter 6, UPSpace Institutional Repository, Retrieved from https://repository.up.ac.za/bitstream/handle/2263/22959/06Chapter6.pdf [Accessed 10 March 2019]

Dudás, G., Boros, L., Kovalcsik, T., Kovalcsik, B. (2017) The visualization of the spatiality of Airbnb in Budapest using 3-band raster representation. Geographia Technica, 12 (1), 23-30. 
Litman. T. (2013), Are vehicle travel reduction targets justified? Evaluating mobility Management policy objectives such as targets to reduce VMT and increase use of alternative modes. Victoria Transport Policy Institute, Retrieved from http://www.vtpi.org/vmt_red.pdf [Accessed 9 March 2019]

Nicoara, P-S. \& Haidu, I. (2014) A GIS based network analysis for the identification of shortest route access to emergency medical facilities. Geographia Technica, 9 (2), 60-67.

Papaioannou, P, and Georgiou, G. (2003), Are traffic demand management (TDM) measures a solution for traffic problems in urban areas? The greek experience, Lund University, Retrieved from http://www.tft.lth.se/fileadmin/tft/dok/KFBkonf/1Georgiou.PDF [Accessed 12 March 2019]

Preece, A. (2001), Evaluating verification and validation methods in knowledge engineering, In Roy, R. (Eds.), Micro-Level Knowledge Management, Springer, London, pp. 123-145 (2001).

Tripathi, K. P. (2011), A review on knowledge-based expert system: concept and Architecture. IJCA Special Issue on Artificial Intelligence Techniques-Novel Approaches \& Practical Applications, $19-23$.

Zain, M. F. M., Islam, N., and Basri, H. (2005), A smart advisory system for mix design of high performance concrete. Advances in Engineering Software, 36(5): 325-337. 